\title{
Comprehensive Evaluation on Exhaust Heat Power Generation System
}

\author{
Zhonglan Hou ${ }^{1, a}$, Xinli Wei ${ }^{1, b}$ Xiangrui Meng ${ }^{2, c}$ Bingxue Zhang ${ }^{3, d}$ \\ ${ }^{1}$ School of Chemical Engineering and Energy, Zhengzhou University, Zhengzhou 450001, China \\ 2 Engineering Research Center of Energy Saving Technologies and Equipments on Thermal \\ System, Ministry of Education (MOE), Zhengzhou 450001, China \\ ${ }^{3}$ Henan Low-carbon Energy Technology Co.,Ltd, Zhengzhou 450000, China \\ ahzlan626@163.com, bxlwei@zzu.edu.cn, ‘xrmeng@zzu.edu.cn, dhnlowcarbon@163.com
}

\begin{abstract}
Keywords: exhaust heat power generation system, comprehensive evaluation, energy conservation and emission reduction, organic Rankine cycle
\end{abstract}

Abstract: Because the exhaust heat is multitudinous and the level of the heat utilization is various, it is significant to exploit the appropriate technologies to convert the waste heat to electricity. In this article, the assessment methods for the exhaust heat power generation system and the comparison on the current exhaust heat power generation technology are conducted. According to this method, the power generating system using exhaust heat is divided into three sections: heat collecting circuit, ORC power generation system and cooling circuit, in which the power generation as the major part of this system is divided into evaporator, expander, electric generator, pump and condenser. The analysis on exhaust heat power generation system of a fertilizer plant was done. The results show that the estimated annual electricity is nearly 20 million $\mathrm{kWh}$, and annual $\mathrm{CO}_{2}$ reduction is $19448 \mathrm{t}$. Annual energy saving income is nearly 10 million yuan(RMB), and lots of cooling water is saved. The 4E hierarchy analysis model is practical and comprehensive analysis method to exhaust heat power generation system.

\section{Introduction}

Reducing industrial energy consumption is becoming an increasingly important issue in China due to the raising costs of both electricity and fossil fuel resources, as well as the tough targets for the reduction in greenhouse gas emissions. A lot of energy saving measures have been proposed to enhance the advantages of cogeneration and different aspects have been taken into account in [1]. Much exhaust heat is generated in many process industries every year. Because of the exhaust heat is multitudinous and the levels of the heat utilization is also various, it is significant to exploit the appropriate technologies to convert the waste heat to electricity. These topics have often been discussed in technical literature[ 2-8].

At the same time, selection of working fluids will help to optimize the ORC performance. In [9-11], this topic was discussed based on different heat source. In [12], considering exergy efficiency and livelier energy cost, the mixture working fluids of R245fa and pentane present lower thermodynamic performance and moderate economic performance than the pure working fluids under the Pareto optimization.

Diversified research methods and performance parameters were used to analyze exhaust heat power generation. Sensitivity analysis and thermo-economic comparison were done by using

Non-dominated sorting genetic algorithm-II in [13], and the method is also used in [14] . Analyses on energy, exergy and entropy were respectively used to optimize exhaust heat power generation with different structures in [15]. Xiao L, et al.[16]put forward multi-objective function by the incorporation of single-objective functions ( net power output, exergy drop of the exhaust gas from inlet to outlet, total exergy destruction rate and system total cost) as the subcritical organic Rankine cycle performance indicator.

In China, Jiangsu Shuangliang eco-energy incorporated company, Zhejiang Kaishan compressor incorporated company and UniEco (Changshu) Co., Ltd. have completed many projects about waste heat recovery. Zhang yan[17] introduced practical application in relevant industries with different 
environment of heat sources. It will promote large-scale popularization and application in exhaust heat power generation.

Generally, exhaust heat power generation has been enhanced on academic research, commercial application, policy support, standards establishment, etc. Different criterion can be adopted to quantify the improvements made with exhaust heat power generation solutions, but it is difficult to compare different solutions or experiment. The existing standard system of evaluation on exhaust heat power generation is not comprehensive enough, and research or projects could only be analyzed from some aspects. Exhaust heat power generation of industrial enterprises in China is ushered in the good opportunities. The application of comprehensive evaluation standard system will help enterprises, investors, researchers and government to have an overall picture of exhaust heat power generation.

\section{Indexes of 4E hierarchy analysis model}

Classical indexes are based on the first law of thermodynamics, in which all the useful energies have the same weight[18-23]. In [24], exergy efficiency has been proposed to analyze energy system. It is important not only how much heat is available but also at what temperature it is available.

Policymakers are mainly interested in exhaust heat power generation in order to promote energy conservation and emission reduction[18,19], but the users and investors are primarily interested in the economic aspects, and therefore economic criteria should also be taken into account. Investment and power consumption of heat exchanger were discussed in[7,17], and combined evaporator with shell-and-tube preheater and flooded evaporator was conformed as the best selection in $[25,26]$.

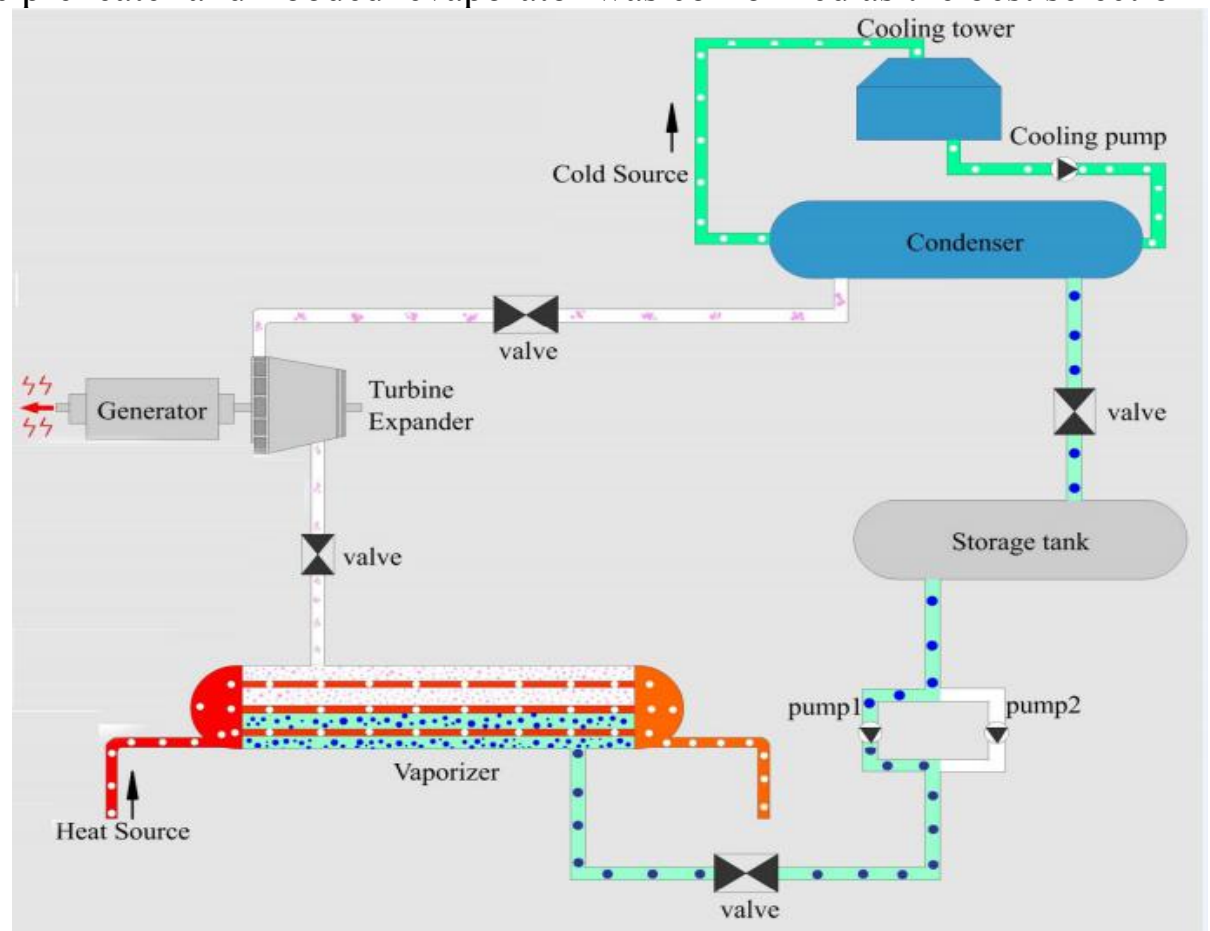

Fig. 1 schematic of exhaust heat power generation system

So the 4E hierarchy analysis model was proposed, here, 4E is Energy, Exergy, Environment and Economy. The entire system was divided into three sections: heat collecting circuit, ORC power generation system and cooling circuit. As we can see from the schematic, ORC system as the major part is composed of evaporator, expander, electric generator, pump and condenser.

According to $4 \mathrm{E}$ model, the entire exhaust heat power generation system, three circuits and main components of ORC power generation system are respectively examined in energy, exergy, environment and economy. 


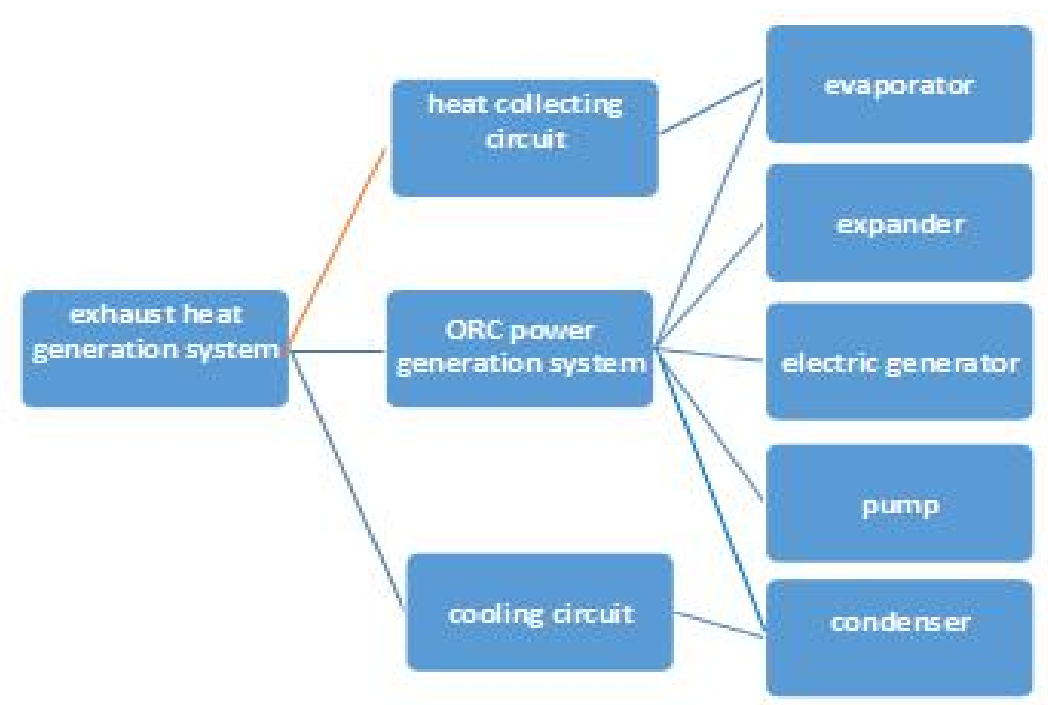

\section{Entire system analysis}

Fig.2 exhaust heat power generation system in three levels

Table 1 presents the first level parameters of the 4E hierarchy analysis model. Seven indexes are introduced to evaluate the entire system: three for energy saving, one for exergy, two for economy aspects, and one for environment aspects.

Table 1 First level indexes of the $4 \mathrm{E}$ model (entire system)

\begin{tabular}{cc}
\hline $4 \mathrm{E}$ & Indexes \\
\hline Energy & total heat recovery and transformation degree \\
& self-used electricity rate annual energy saving \\
Exergy & total exergy efficiency \\
Economy & generating cost annual energy saving income \\
Environment & annual environmental protection benefit
\end{tabular}

Total heat recovery and transformation degree can be expressed as follows:

$$
\eta=\frac{E L}{Q_{H}} \times 100 \%
$$

where, $E L$ is net electric output power of the entire system, $\mathrm{kW} ; Q_{H}$ is heat acquired from exhaust heat, $\mathrm{kW}$.

Self-used electricity rate could clearly show the link between power generation and electricity consumption by system itself. It is defined as:

$$
R_{w i, s y s}=\frac{E L_{i}}{E L} \times 100 \%
$$

One of the most important comparisons between exhaust heat power generation system and exhaust heat resource without recovery is annual energy saving, which is calculated as:

$E=e_{W} \cdot E L$

In China, $e_{w}$ means nationwide energy consumption per unit of electricity of last year, $\mathrm{kg}$ ce $/ \mathrm{kWh}$. The number is $0.324 \mathrm{kgce} / \mathrm{kWh}$ in 2015 .

Based on the second law of thermodynamics, total exergy efficiency is defined as:

$$
\varepsilon=\frac{E X_{s y s}^{u}}{E X_{s y s}^{a}} \times 100 \%
$$

where $E_{s y s}^{u} 、 E_{s y s}^{a}$ respectively refer to the used and available exergy of the entire system, $\mathrm{kW}$.

The main costs of system investment $C_{\text {total }}$ are: equipment, installation, working fluids purchase costs, and maintenance. Generating cost can be written as: 


$$
C_{E L}=\frac{C_{\text {total }}}{E L}
$$

Annual energy saving income is calculated as:

$$
C_{s y s}=C_{E L} \cdot E L
$$

where $C_{E L}$ is electricity price the same year, yuan $/ \mathrm{kWh}(\mathrm{RMB})$.

Benefit of environmental protection is measured by equation (7):

$$
E N=E F_{\text {grid, } y} \cdot E L
$$

Where $E F_{\text {grid,y }}$ is China regional power grid baseline emission factor in recent year, $\mathrm{tCO}_{2} / \mathrm{MW}$. For example, in central China, the value is $0.9724 \mathrm{tCO}_{2} / \mathrm{MW}$.

\section{Three circuits analysis}

As previously mentioned, the power generating systems were divided into three sections: heat collecting circuit, ORC power generation system and cooling circuit. Table 2 presents the second level parameters of the 4E model. Twenty-one indexes are introduced to evaluate three circuits of exhaust heat power generation from the aspects of the energy, exergy, economic benefit and environment protection.

In [27], the exergy efficiency of element $i$ is defined as the ratio of used exergy of element $i$ to the available exergy for the same element. The exergy efficiency of three circuits can be calculated in the same way. Cost ratio clearly indicates the weight of investment in different circuit and it is always different in specific condition. For example, the cost of heat collecting circuit mentioned in [7] is $80 \%-90 \%$, while the index of case studied in this article is only 5\%. Cost per heat, cost per exergy and cost per electric can also indicate difference in economy.

Environmental protection benefits of three circuits are calculated in accordance with specific conditions. To heat collecting circuit, the reduction of thermal pollution, flue gas and dust is apparent.

\begin{tabular}{|c|c|c|}
\hline $4 \mathrm{E}$ & Sections & Indexes \\
\hline \multirow{3}{*}{ Energy } & heat collecting circuit & heat recovery degree \\
\hline & ORC power generation system & $\begin{array}{c}\text { thermoelectric transformation ratio } \\
\text { self-used electricity ratio }\end{array}$ \\
\hline & cooling circuit & $\begin{array}{c}\text { thermal efficiency } \\
\text { working fluid consumption }\end{array}$ \\
\hline \multirow{3}{*}{ Exergy } & heat collecting circuit & exergy efficiency \\
\hline & ORC power generation system & $\begin{array}{l}\text { exergy efficiency } \\
\text { exergy loss degree }\end{array}$ \\
\hline & cooling circuit & exergy efficiency \\
\hline \multirow{3}{*}{ Economy } & heat collecting circuit & $\begin{array}{c}\text { cost ratio } \\
\text { cost per heat recovery } \\
\text { cost per exergy }\end{array}$ \\
\hline & ORC power generation system & $\begin{array}{c}\text { cost ratio } \\
\text { cost per electric }\end{array}$ \\
\hline & cooling circuit & $\begin{array}{c}\text { cost ratio } \\
\text { cost per heat } \\
\text { cost per exergy }\end{array}$ \\
\hline \multirow{3}{*}{ Environment } & heat collecting circuit & environmental protection benefit \\
\hline & ORC power generation system & $\begin{array}{c}\text { environmental protection benefit } \\
\text { environmental impact }\end{array}$ \\
\hline & cooling circuit & environmental impact \\
\hline
\end{tabular}
To ORC system, leakage pollution of working fluid should also be considered.

Table 2 Second level indexes of the $4 \mathrm{E}$ model (three circuits) 


\section{ORC power generation system analysis}

As the major part of exhaust heat power generation system, the ORC power generation system is divided into evaporator, expander, electric generator, pump and condenser. Energy and exergy efficiency of evaporator, condenser and expander is calculated respectively in clear boundary. Isentropic efficiency of pump and expander is examined too. The ratio of electric power of the generator to output power of the expander is calculated as:

$$
R_{e, w}=\frac{E L}{W} \times 100 \%
$$

where, $W$ is output power of expander, $\mathrm{kW}$; $E L$ is output electricity, $\mathrm{kW}$.

Researchers are interested in indexes of the third level. For deep research on ORC system, some researchers focused more attention on this part. In view of different purpose, researchers can set new indexes to evaluate performance of equipment and system.

\section{Case study}

This paper takes the urea workshop of a fertilizer plant for example. The annual output of the urea is $800,000 \mathrm{t} / \mathrm{a}$ in the fertilizer plant. Before implementing scheme of ORC power generation, high temperature regulation water of high pressure ammonium carbamate cooler is cooled by circulating cooling medium. By this cooling method, not only a large amount of heat is wasted, but also the cooling medium system itself will consume considerable electric energy. Organic refrigerant R245fa is used for this project, and the installed capacity reaches $2400 \mathrm{~kW}$. Some parameters of exhaust heat power generation system with different working conditions are shown in Table 3:

Table 3 Some parameters of exhaust heat power generation system in ammonium carbamate production process of a fertilizer plant

\begin{tabular}{|c|c|c|c|c|}
\hline \multirow[b]{2}{*}{ Parameters } & \multicolumn{3}{|c|}{ Conditions } & \multirow[b]{2}{*}{$\mathrm{D}$} \\
\hline & A & B & $\mathrm{C}$ & \\
\hline hot warter flow $/ \mathrm{t} / \mathrm{h}$ & 300 & 300 & 300 & 300 \\
\hline inlet temperature of hot water $/ \mathrm{C}$ & 143 & 143 & 143 & 143 \\
\hline outlet temperature of hot water $/ \mathrm{C}$ & 120 & 120 & 120 & 119.5 \\
\hline inlet temperature of cooling warter $/ \mathrm{C}$ & 25 & 25 & 32 & 15 \\
\hline outlet temperature of cooling warter $/ \mathrm{C}$ & 35 & 33 & 40 & 23 \\
\hline net output power $\mathrm{kW}$ & 1062 & 1077 & 979 & 1141 \\
\hline self-used electricity $/ \mathrm{kW}$ & 93 & 93 & 93 & 93 \\
\hline
\end{tabular}

According to 4E model, indexes can be calculated and classified as Table 4.

Table 4 Some indexes of the $4 \mathrm{E}$ model in exhaust heat power generation system

\begin{tabular}{lll}
\hline Name & Indexes & Data \\
\hline & annual energy saving/tce & 64800 \\
entire system & $\begin{array}{l}\text { generating cost/ (yuan/ } \mathrm{kWh} \text { ) } \\
\text { annual energy saving income/yuan(RMB) } \\
\text { annual environmental protection benefit } \\
\left.\text { (reduction of } \mathrm{CO}_{2}\right) / \mathrm{tCO}_{2}\end{array}$ & 0.20 \\
& 10 million \\
& & 19448 \\
\hline
\end{tabular}

\begin{tabular}{|c|c|c|c|c|}
\hline \multirow{2}{*}{\multicolumn{2}{|c|}{ Heat collecting system }} & \multicolumn{2}{|c|}{ Conditions } & \multirow{3}{*}{$\mathrm{D}$} \\
\hline & & $\mathrm{A}$ & $\mathrm{B} \quad \mathrm{C}$ & \\
\hline & cost ratio $/ \%$ & & 5 & \\
\hline \multirow{4}{*}{ ORC system } & thermoelectric transformation ratio/\% & 12.1 & $\begin{array}{ll}12.2 & 10.7\end{array}$ & 13.0 \\
\hline & self-used electricity ratio $/ \%$ & 8.1 & $\begin{array}{ll}7.9 & 8.7\end{array}$ & 7.5 \\
\hline & cost ratio $/ \%$ & & 90 & \\
\hline & cost per electric/(yuan/kWh) & & 0.18 & \\
\hline \multirow[t]{2}{*}{ cooling system } & cooling water consumption/ $\mathrm{t} / \mathrm{h}$ & 633 & $782 \quad 759$ & 802 \\
\hline & cost ratio $/ \%$ & & 5 & \\
\hline turbine & isentropic efficiency $/ \%$ & 84 & $84 \quad 84$ & 82 \\
\hline
\end{tabular}


By using original heat collecting and cooling system, main investment in engineering is ORC power units. As indexes of entire system shown, appreciable income, energy saving and environment benefit will be acquired.The working condition of heat collecting and cooling system is similar, and numeric of self-used electricity of power generation system and turbine isentropic efficiency of different cases are approximately equal to each other.

There is a positive correlation between net output power and heat-to-electric ratio, so we can focus more attention on difference between cooling water consumption and heat-to-electric ratio. As working fluids of cooling system, cooling water need to purchase, and water supply need energy. More net output power and less cooling water supply are both important to enterprise investor. So, choosing a way which can make best benefits based on the balance of cooling water supply and net output power is next step.

Exergy analysis on research is common, but it is also necessary for engineering. Great attention should be paid to exergy analysis on engineering. Because more attention was focused on ORC power units, there are few parameters about heat collecting system, cooling system and equipments. But it is important to have an overall understanding for system continuous improvement.

\section{Conclusion}

In the paper, a new $4 \mathrm{E}$ hierarchy analysis model is presented based on exhaust heat power generation system of ORC. According to the 4E model, all indexes of entire power generating system, three sections of entire system, and the ORC power generation system are calculated from energy, exergy, environment and economy, respectively.

The analysis on exhaust heat power generation system of a fertilizer plant was done. The results show that the estimated generatingncapacity is nearly 20 million $\mathrm{kWh} / \mathrm{a}$ (equal to $64800 \mathrm{tce} / \mathrm{a}$ ), the emission reduction of $\mathrm{CO}_{2}$ is $19448 \mathrm{t} / \mathrm{a}$, the energy saving income is nearly 10 million RMB/a, and lots of cooling water is saved.

\section{Acknowledgements}

This work was supported by the Scientific and Technological Planning Projects of Henan Province, China (No.162102310504) and the Foundation of State Key Laboratory of Coal Combustion (No. FSKLCC1410).

\section{References}

[1] Ministry of Industry and Information Technology of the People's Republic of China, The 12th five-year plan of industrial energy saving(2012),Available at:

http://www.miit.gov.cn/n11293472/n11293832/n11293907/n11368223/n14475991.files/n14474195. pdf. (last access: March 2016)

[2]Richard Law, Adam Harvey, David Reay, Opportunities for low-grade heat recovery in the UK food processing industry,Applied Thermal Engineering 53(2013)188-196.

[3]Bertrand F. Tchanche, Gr. Lambrinos, A. Frangoudakis, G. Papadakis, Low-grade heat conversion into power using organic Rankine cycles - A review of various application, Renewable and Sustainable Energy Reviews 15(2011)3963-3979 .

[4] A. Schuster, S. Karellas, E. Kakaras, H. Spliethoff, Energe tic and economic investigation of Organic Rankine Cycle applications, Applied Thermal Engineering 29(2009) 1809-1817

[5] X.L. Ma , H. Wang, X.L. Wei , X.R. Meng, K.X.Yang. Feasibility study of recovery waste heat of flue gas using organic Rankine cycle,Journal of Zhengzhou University(Engineering Science) 34(2013)55-58.

[6] Long Shao, Xinling Ma, Xinli Wei, Zhonglan Hou, Xiangrui Meng, Design and experimental study of a small-sized organic Rankine cycle system under various cooling conditions[J], Energy 130 (2017) 236-245.

[7] Z.Q.Wang, X.X. Xia, N.J. Zhou, Thermo-economic analysis of powergenera ting system based on organic Rankine cycle for low grade waste heat recovery, Industrial Heating 42(2013),33-36.

[8]Marco F. Torchio, Energy-exergy, environmental and economic criteria in combined heat and power (chp) plants: indexes for the evaluation of the cogeneration, Energies 6(2013)2686-2708. 
[9] D.X. Wang, X. Ling, H.Peng, Performance analysis of double organic Rankine cycle for discontinuous low temperature waste heat recovery, Applied Thermal Engineering, 48(2012)63-71. [10] T.L. Li , J.L. Zhu , W. Zhang, Cascade utilization of low temperature geothermal water in oilfield combined power generation, gathering heat tracing and oil recovery, Applied Thermal Engineering 40(2012)27-35.

[11]D.X. Wang, X. Ling, H.Peng, L. Liu, L.L. Tao, Efficiency and optimal performance evaluation of organic Rankine cycle for low grade waste heat power generation, Energy 50(2013)343-352.

[12]Y.Q. Feng, T.C. Hung, Y.N. Zhang, B.X. Li, J.F. Yang, Y. Shi, Performance comparison of low-grade ORCs (organic Rankine cycles) using R245fa, pentane and their mixtures based on the thermoeconomic multi-objective optimization and decision makings, Energy 93 (2015) 2018-2029. [13]Y.Q. Feng, Y.N. Zhang, B.X. Li, J.F. Yang, Y. Shi, Sensitivity analysis and thermoeconomic comparison of ORCs(organic Rankine cycles) for low temperature waste heat recovery, Energy 82 (2015)664-677.

[14] Y. Shi, Performance study and optimization of organic ranking cycle using medium and low temperature heat, Harbin Institute of Technology, 7(2015).

[15]T.L. Li, Thermodynamic optimization and experimental study on organic rankine cycle for low-and-medium-grade geothermal power generation, Tianjin University,9(2013).

[16] L. Xiao, S.Y. Wu, T.T. Yi, C. Liu, Y.R. Li, Multi-objective optimization of evaporation and condensation temperatures for subcritical organic Rankine cycle, Energy 83(2015)723-733. [17]Y. Zhang, The heat extraction theory and application study of low-temperature heat, Tianjin University, 11(2013).

[18]The 6th order of National Development and Reform Commission of the People's Republic of China,Fixed asset investment project interim measures for energy saving assessment and review(2010), Available at: http://www.gov.cn/gongbao/content/2011/content_1792048.htm.(last access: 4th March 2016)

[19] The seventy-seventh order of The President of the People's Republic of China, The environmental impact assessment law of the People's Republic of China

(2002), Available at: http://www.gov.cn/gongbao/content/2002/content_61822.htm.(last access: 29th December 2017)

[20] State Bureau of Quality Technical Supervision of China, General Principle of Energy Audit on Industrial and Commercial Enterprise(GB/T 17166-1997),(Standards press of china,1997)

[21] General Administration of Quality Supervision, Inspection and Quarantine of the People's Republic of China, Standardization Administration of China, Calculating methods of energy saved for enterprise(GB/T13234-2009),(Standards press of china, 2009)

[22] General Administration of Quality Supervision, Inspection and Quarantine of the People's Republic of China, Standardization Administration of China, The norm of energy consumption per unit product of general coal-fired power set, GB21258-2013 (Standards press of china,2014) [23] General Administration of Quality Supervision, Inspection and Quarantine of the People's Republic of China, Standardization Administration of China, General principles for Calculation of the comprehensive energy consumption, GB/T2589-2008, (Standards press of china,2008) [24]General Administration of Quality Supervision, Inspection and Quarantine of the People's Republic of China, Standardization Administration of China, Technical guides for exergy analysis in energy system, GB /T 1490 9- 2 005, (Standards press of china,2006)

[25] X.X. Chen, Study on screw expander power generation technology, Tianjin University, 2011

[26] L.L. Wei, Y.F. Zhang, Y.C.Mu, Study of evaporator in low-temperature energy conversion system using organic Rankine cycle(ORC), Cryogenics, 208(2015)31-36

[27] Ch. Somayaji, First and second law analysis of organic rankine cycle, Mississippi State University,5(2008) 